\title{
\#SportToo: Implications of and Best Practice for the \#MeToo Movement in Sport
}

\author{
Mitch Abrams \\ Learned Excellence for Athletes \\ Michelle L. Bartlett \\ West Texas A\&M University
}

The \#MeToo movement has brought long needed attention to the epidemic of sexual assault and sexual violence. In the world of sports, the need to prevent and address such acts requires individuals with training in clinical, forensic and sport psychology. These professionals must have particular understanding of the dynamics of sexual violence within the athletic and sport culture. This paper serves to highlight context-specific approaches to pertinent identification and treatment issues. An overview of sexual abuse victim and perpetrator identification will be offered. In addition to the introduction of risk assessment and recommendation of comprehensive prevention programming, treatment needs in the athletic context will be explored. Group-level interventions currently being utilized will be reviewed, recommended topic areas to be covered in protocols will be enumerated and suggestions for systemic and cultural change in the sport domain will be offered.

Keywords: assessment, sexual assault, sport, violence

With enhanced media attention to the epidemic of sexual assault and sexual violence in the world of sports, and in particular college sports, an opportunity to address and prevent such acts is presenting for individuals with a unique skill set. The \#MeToo movement, founded by Tarana Burke in 2006, may be the most widely seen social media phenomenon demonstrating the importance of a meaningful response by those involved in sports. Individuals that have training in two vital areas: clinical psychology/counseling and in sport and performance, particularly in understanding athletic and sport culture, bring pragmatic expertise to the table. Specifically, clinical sport psychologists with forensic training can establish themselves as a critical piece in the call to address and remediate these prominent issues in today's sport landscape. The problem of sexual violence in sports sits at the nexus of the subspecialties of clinical psychology, sport psychology, and forensic psychology.

This paper serves to provide an overview of context-specific approaches to pertinent identification and treatment issues. An overview of sexual abuse victim

Abrams is with Learned Excellence For Athletes, Fords, NJ. Bartlett is with the Dept. of Sports \& Exercise Sciences, West Texas A\&M University, Canyon, TX. Address author correspondence to Mitch Abrams at MitchAbramsPsyD@gmail.com and Michelle Bartlett at mbartlett@wtamu.edu. 
and perpetrator identification will be offered along with a critical examination of prevention programming. Risk assessment methodology will be reviewed in the context of factors that contribute to a culture that tolerates sexual assault. Grouplevel interventions currently being utilized will be reviewed, recommended topic areas to be covered in protocols will be enumerated, and suggestions for systemic and cultural change in the sport domain will be offered.

\section{Sexual Assault and Abuse Identification}

Prior to the Larry Nassar scandal at Michigan State University and U.S. Gymnastics, there has been concern about sexual abuse and assault in sport. Dr. Celia Brackenridge captured these issues in her seminal tome Spoilsports: Understanding and Preventing Sexual Exploitation in Sport, published in 2001. Before this, former NHL hockey player Sheldon Kennedy and another unnamed player came forward and accused their former coach Graham James of sexually abusing them for years between 1984 and 1995. Later, Theo Fleury, another prolific NHL star came forward with his story that mirrored the abuse Kennedy had endured. They collectively reported that James had abused several male hockey players under his supervision for many years. This was long before the Jerry Sandusky abuse at Penn State Football, hidden under the guise of camps for underprivileged or troubled youth. Perpetrators are not only coaches and sport staff, but athletes, as well. In 2013, Jameis Winston, then quarterback of the Florida State University football team, was accused of sexual assault. No charges were filed, however, in 2016, the university paid $\$ 950,000$ to settle a lawsuit brought by the victim alleging a violation of Title IX by FSU in handling her complaint. Winston was later accused of groping an Uber driver and was suspended three games of the 2018 season by the NFL. In 2016, former NFL safety Darren Sharper was convicted of multiple charges of drugging and sexually assaulting several women across many cities. He is currently serving a 18-year sentence in federal prison and will have to report as a sex offender when he completes his incarceration. In contrast, former Stanford University swimmer, Brock Turner, received a mere 6-month sentence for a sexual assault conviction on an unconscious woman outside a campus fraternity house (see also Abrams, 2010, pp. 217-219). In all of the cases, there was the opportunity for law enforcement, sports administration, governing bodies, and many other adults to intercede, but for a variety of reasons, they all failed to do so; leaving countless victims in their wake.

These represent only a few of the sexual abuse scandals that have existed in the sports world.. Sexual grooming itself is defined by Craven, Brown, and Gilchrist (2006, p. 297) as a "process by which a person prepares a child, significant adults and the environment for the abuse of this child. Specific goals include gaining access to the child, gaining the child's compliance, and maintaining the child's secrecy to avoid disclosure." The process of recruitment in sports provides an opportunity for adults to have significant authority and control over the athletes that want to compete for them, and parents often trust that their children are going to be safe, regardless of whether it is accurate for them to do so. Coaches who are successful with improving performance and/or helping the athlete advance to higher levels of competition may sometimes be erroneously presumed to be equally 
concerned with the athletes' psychological health and development. Simultaneously, there are many coaches that are tremendous role models, and some of which have literally saved the lives of athletes who may have gone down treacherous paths without their guidance. The purpose of these statements is not to demonize sports, but to recognize that sports can create an environment conducive to the recruiting and grooming of victims by a sexual predator.

Sports leagues have attempted to subvert the potential for sexual predators to access athletes by utilizing criminal background checks. Unfortunately, criminal background checks are inadequate if the coach (or doctor, or any other predator in the authoritative milieu) has not previously been caught, arrested and/or convicted. Sexual predators may be particularly adept at avoiding apprehension and thus a "clean" background check may give the illusion of safety, setting the stage for precarious situations. It is then of paramount importance to understand that sex offenders are not a homogenous group that all have the same proclivities, grooming patterns, preferences, attitudes, presentations, etc. Identifying perpetrators requires understanding the many criminogenic factors that contribute to sexual offending. Identifying victims requires understanding of the often complex presentation of trauma-related symptoms.

\section{Victim Identification}

When screening for sexual abuse trauma-related symptoms, it is important to understand that the groomed, abused athlete may not present symptoms in a typical manner. A victim may present as confident and well-adjusted at some times, and at other times they may present as scared, irritable or angry. In addition, the victim may appear depressed or anxious or traumatized with inconsistent presentations. This is partially due to the abuser intentionally keeping their victim off guard, unbalanced and thus, easier to control. For example, the abuser may shower the victim with praise and gifts while alienating them from watchful parents, then later threaten the athlete with harm if they should tell others about the abuse. This is one of the ways offenders may groom their victims by separating them and ingratiating themselves with the targeted victim, therefore setting the stage for the abuse to occur.

Furthermore, where one might anticipate seeing "traditional" symptoms of simple post traumatic stress disorder (PTSD), such as flashbacks, nightmares, intrusive thoughts, emotional hyper-reactivity, etc., many people that have endured long-term abuse develop complex PTSD (c-PTSD), which presents differently (Roth, Newman, Pelcovitz, van der Kolk, \& Mandel, 1997). C-PTSD presents with emotional dysregulation, but symptoms also include shame and guilt, distorted perceptions of self, relationship difficulties, dissociation, and low-level paranoia. Simple and/or Complex PTSD, eating disorders, depressive disorders, and anxiety disorders all have been associated with trauma. Substance abuse is a mechanism sometimes utilized by the victim to self-medicate the trauma-related emotional pain. Furthermore, there will be some who develop symptoms that spontaneously remit, and there will be some who never become symptomatic at all. Because of a sport culture that encourages obedience and the suppression of emotions (Sinden, 2013), athletes may struggle in ways that don't mimic traditional clinical features. The clinician must be educated about trauma-informed care and the athlete culture, 
to maximize the likelihood of identifying symptoms the athlete may have ambivalence about sharing.

In summary, the many different strategies used by the perpetrators leads to many different reactions by victims. It is important that those working with potential victims of sexual assault are aware that compared with presenting traditional trauma symptoms (flashbacks, nightmares, emotional reactivity, etc.) consistently, the athlete victimcan present symptoms of sexual abuse inconsistently. For example, the victim may portray confidence one day, and on another may look like a shell of themselves; frightened, fragile, and confused.

Thus, it is critical to refer the athlete to a clinical sport psychologist who has experience in identifying trauma in sports. If the sport organization does not have such a referral source, one should be sought out immediately. The American Psychological Association provides a resource to find a local sport psychologist on their website at https://locator.apa.org. Again, advocates may be well-intended and can assist with policy changes, but it is difficult to help without having experience working with both victims and perpetrators of sexual abuse. . .especially those that have navigated the world of athletics and understand the culture of sport.

\section{Sexual Violence Risk Assessment}

If/when an organization identifies a perpetrator suspected of abuse or assault, this individual subsequently needs to be assessed to determine if/what treatment they would benefit from. Often the organizational patterns have been to either cover up the actions or dismiss them from the institution. If the latter is chosen, and no assessment is completed, the perpetrator leaves and finds victims elsewhere. Further, when the alleged perpetrator is an athlete and not a member of the staff, there are added factors that schools and athletic departments struggle with. Resources invested in the athlete will be lost and the hopes of the athlete assisting school athletic success (with accompanying increase in revenue) may leave with them. Instead of reducing victims, it increases victims elsewhere, while protecting the "brand" of the university or organization.

There are a variety of tools available to assess risk and determine likelihood of future offending. However, these tools have yet to be normed on athlete populations. Since sex offending is a comparatively low base-rate crime and there have not been sufficient athletes who have been identified as perpetrators, it is difficult to study athletes-as-perpetrators and develop specialized offender risk assessment tools accordingly. This may be an area of future research, but in the absence of such tools, utilization of current methodology is an appropriate mechanism to assess violence in sport domains.

Historically, risk assessment utilized three models: unstructured clinical decision making, actuarial decision making, and Structured Professional Judgment. Unstructured clinical decision making is the oldest and most widely used method that involves no specific guidelines for the evaluator. They "simply" offer their clinical opinion without support of well-considered static and dynamic risk factors and it is supported by their professional qualifications and credentials. This has been criticized in the literature for lacking reliability, validity and accountability (Litwack \& Schlesinger, 1999). 
The actuarial method utilizes algorithmic tools that predict violence by comparing an individual to a norm-based reference group and provide a more precise, probabilistic estimate of future violence. This is more mechanical, but it improves upon the poor reliability and validity of unstructured approaches (Grove \& Meehl, 1996; Litwack, 2001; Quinsey et al., 1998). However, because of the removal of professional discretion and rigidity of actuarial approaches (Douglas \& Kropp, 2002; Hart, 1998), the forensic field has evolved further by utilizing the Structured Professional Judgment approach, which has been popularized by those focusing on recidivism prevention utilizing the Risk Needs Responsivity (RNR) model (Andrews \& Bonta, 1998). This process allows for professional discretion in adjusting risk conclusions from the actuarial predictions with consideration of other risk-related information. For example, a meta-analysis of sexual offender recidivism (Hanson \& Bussiere, 1998) noted two broad factors were associated with sexual recidivism: deviant sexual interests and antisocial orientation/lifestyle instability. Similarly, Malamuth et al. (1996) identified in his Confluence Model, hostile masculinity and impersonal sexual orientation as supported precursors to increased risk of sexual violence.

The Structure Professional Judgment approach has been shown to have good validity (Douglas \& Webster, 1999) and discriminates well between recidivists and non-recidivists in retrospective research (Hanson \& Morton-Bourgon, 2004). It is recommended that risk assessment of athletes utilizes actuarial instruments when possible and support the obtained data with other information gleaned by psychological testing, clinical interview and collateral information. Moreover, the ability to assess an individual's likelihood of future assault is actually a conglomeration of very specialized skills that most sport counselors have not been trained with. It is critical for every sport organization to know what medical and/or mental health professionals they have access to and what skillsets those professionals possess, as well as how to gain access to other professionals with required expertise if needed. Ideally, this would be a clinical sport psychologist with forensic training.

A non-exhaustive list of tools that assess risk of recidivism and then can be synthesized in the context of other empirically supported criminogenic factors follows. These include the Historical Clinical Risk Management-20, Version 3 (HCR-20; Douglas, Hart, Webster, \& Belfrage, 2013), the Spousal Assault Risk Assessment (SARA; Kropp, Hart, Webster, \& Eaves, 1995), the Static-99R (Phenix, Helmus, \& Hanson, 2012), and the Psychopathy Checklist-Screening Version (PCL-SV; Hart, Cox, \& Hare, 1995). Other personality measures used to assess psychological factors that may also detect an individual's potential for violence include the Personality Assessment Inventory (PAI; Morey, 2007), the Minnesota Multiphasic Personality Inventory - 2nd Edition, (MMPI-2; Butcher et al, 2001), the State Trait Anger Expression Inventory - 2nd Edition (STAXI-2; Spielberger, 1999), and the Rorschach Inkblot Test (Weiner, 2005), primarily utilizing the Comprehensive System (Exner, 2002), which has proved to be very useful in forensic assessments.

The utilization of RNR models allow for assessment of risk and recommendations for treatment. Though sex offender treatment has not been specifically modified for people employed in or participating in athletics, and the specifics of sex offender treatment go beyond the scope of this article, it is prudent to extend already established programs that focus on building strengths that compensate for 
criminogenic risk factors, such as the Good Lives Model (Ward, 2002; Ward, Melser, \& Yates, 2007; Willis \& Ward, 2010), to athlete populations that demonstrate sexual assault risk factors.

\section{Sexual Assault Prevention}

There is little doubt that sexual assault is an epidemic, especially on college campuses. Among undergraduate students, $23.1 \%$ of females and $5.4 \%$ of males experience rape or sexual assault through physical force, violence, or incapacitation (Cantor et al., 2015) with an additional 25\% of transgender college students experiencing sexual assault while on campus (New, 2015). The rate of sexual assaults on campuses has remained relatively unchanged over the past 20 years (Fedina, Holmes, \& Backes, 2016). Conley et al. (2017) asserted that sexual assault is the most common form of violence on college campuses, yet only about $12 \%$ are sexual assaults are reported (Coray, 2016). One in nine girls and one in 53 boys under the age of 18 experience sexual abuse or assault at the hands of an adult and females ages 16-19 are four times more likely than the general population to be victims of rape, attempted rape, or sexual assault (Finkelhor, Shattuck, Turner, \& Hamby, 2014). Women of the age of 18-24 are at the highest risk for sexual assault compared to the general population (Robers, Kemp, Rathbun, Morgan, \& Snyder, 2014). Some researchers have found lifetime incident rates of childhood sexual abuse for females to be 1 in 4 (25\%) and 1 in $6(16 \%)$ for males (Dube et al., 2005). Though the perpetrators tend to be males and acquaintances that the victim knows, more males are victimized than one might assume (Bullock \& Beckson, 2011).

There have been some researchers who have argued that athletes are more likely to perpetrate sexual violence (e.g. Eskenazi, 1990) than non-athletes. Research has found that involvement in contact versus non-contact sports may not contribute to higher levels of aggression against women (Marchell, 1998; Smith \& Stewart, 2003). Recently, Navarro and Tewksbury (2017) found that athletes and non-athletes were similar in the degree of rape myth acceptance (RMA) with athletes reporting stronger agreement than nonathletes did. Interestingly, in this same study, the authors found "an unanticipated and inverse relationship between Greek organization membership and RMA; Greeks were not particularly adherent to rape myths," as it could be that Greek organizations desire to combat their stereotype. Other studies have found that athletic participation has been identified as an uninfluential factor in rape myth acceptance (Humphrey \& Kahn, 2000). Caron, Halteman, and Stacy (1997) and Smith and Stewart (2003) concluded that there was no significant difference between athletes and non-athletes on aggressive sexual behavior. They opined that thecharacteristics of athletes themselves rather than their athletic participation must be considered further in examining the presumed link between athletes and sexual assault.

However, there may be factors in sport culture that may contribute to assaultive behaviors if left unchecked. These may include hostile (or toxic) masculinity, especially when paired with a culture of impersonal sex (Malamuth et al., 1996), rape supportive attitudes or rape myth acceptance (attitudes that shift the blame for sexual assault from the perpetrator to the victim (Holland \& Cortina, 2017; see also Abrams, 2010, p. 234), sense of entitlement, group dynamics that lead to 
Groupthink (Janis, 1972) and deindividuation, drug/alcohol use, and a lack of consequences. Hence, this is why these must be addressed in comprehensive prevention programs.

The most prolific models used to prevent sexual assault have centered upon Bystander Intervention models. This is interesting considering the fact that Bystander Interventions were the descendent of the Bystander Effect, or Bystander Apathy (Darley \& Latane, 1968), which found that individuals do not offer help to a victim when other people are present. The probability of help is inversely related to the number of bystanders and there is a diffusion of responsibility. It has been found that if one person stands up, more are likely to do so, but if no one helps, people are left wondering what the right thing to do is (Fischer et al., 2011). Other barriers to bystander intervention models include: unconscious racial bias (Katz, Merrilees, Hoxmeier, \& Motisi, 2017), rape myth acceptance, bystander efficacy, alcohol use/intoxication, peer perceptions, perceptions of sexual assault severity, and gender of the bystander (Labhardt, Holdsworth, Brown, \& Howat, 2017), with males less likely to intervene (Leone \& Parrott, 2019).

Jackson Katz' (1995) Mentors in Violence Prevention (MVP Program) is a widely disseminated sexual violence prevention model in sports, which utilizes a bystander-based approach. The research does not support that this is an effective program, though it tends to be well-received by the audience (Williams \& Neville, 2017). Also, college-level bystander programs have increased participants' feelings of self-efficacy for and frequency of intervening in situations that could lead to a sexual assault (Katz \& Moore, 2013), based upon self-report. The NCAA has historically supported bystander-based approaches, as well (NCAA, n.d.).

However, when examined more closely, it has been recognized that actively intervening in a peer or stranger's aggressive behavior is a challenging task even for well-trained adults (Casey \& Ohler, 2012) and, further, youth identified more barriers than facilitators to bystander behavior. For adolescents, the prospect of intervening is laden with real social and sometimes physical risks (Storer, Casey, \& Herrenkohl, 2016). This has led Leone et al. (2017) to conclude, although bystander intervention programs have been identified as a promising prevention strategy for sexual aggression, a recent meta-analysis suggests they have a stronger impact on attitudes and behavioral intentions than on actual bystander behavior (Katz \& Moore, 2013).

The best evidence that bystander interventions are necessary but not sufficient is the fact that while bystander interventions have been the primary modality of prevention for decades, the rate of reported sex crimes on college campuses has continued to surge and Bureau of Justice Statistics noted that campus sexual assaults jumped from about 4,000 in 2012 to 5,000 in 2013 (Robers et al., 2014). There are consistently increasing reports of sexual assault complaints through the years despite the ongoing attempts at prevention. However, this increase in reporting may also signify greater access to knowledge on how to report.

Other approaches include "Shotgun approaches," such as rookie symposia or single-time viewings, which may be moving and momentarily eye-opening, but these approaches don't change culture by themselves and can often fall out of the athletes' consciousness shortly after the presentations. Findings suggest that longer term interventions than are typically presented may be one important aspect of producing stable change over time (Heppner et al., 1999). Additionally, in their 
review of college sexual assault prevention programs, Vladutiu, Martin, and Macy (2011) found that effective sexual assault prevention programs are professionalfacilitated, targeted at single-gender audiences, and offered at various times throughout students' tenure at college. They are workshop-based or offered as classroom courses with frequent and long sessions. Program content should include gender-role socialization, risk education, rape myths, rape attitudes, rape avoidance, men's motivation to rape, victim empathy, dating communication, controlled drinking and/or relapse prevention (Vladutiu, Martin, \& Macy, 2011).

When pairing the increasing sexual assault reports with the correspondingly large settlements in Title IX lawsuits (most settlements are not made public), it becomes obvious that more comprehensive programs for sexual assault prevention are necessary. Moreover, because there are factors in the athlete culture that may contribute to sexual assault, programming should be tailored to athlete populations while being mindful that there are heterogenous subcultures inside the sports world. Admittedly, it is difficult to know how successful programs are because dependent variables such as decreases on measures with high face validity (such as rape supportive attitudes, male dominance/power, reporting that the subjects feel more equipped to stand up when witnessing a violent event, and victim empathy), do not reliably lead to a change in behavior. Nonetheless, it is the opinion of the authors that there is a need for more aggressive models that focus on the accountability of the perpetrator. These are the conditions that led to the development of the Abrams Plan for Violence Prevention, Assessment, and Treatment (Abrams, 2010).

\section{Abrams Plan for Violence Prevention, Assessment, and Treatment}

At the core of the Abrams Plan for Violence Prevention, Assessment, and Treatment is the Risk Needs Responsibility (RNR) model developed by Don Andrews and James Bonta in the late 1990s, which has proliferated the forensic psychology world for the past twenty years. As mentioned earlier, the philosophy focuses on the fact that offenders have risk factors that contribute to their criminality and each risk factor has a treatment need to which it corresponds. Finally, there is appreciation that not all risk factors have the same responsivity to treatment and that should be considered in the context of how treatment is formulated for offenders.

Abrams (2017a, 2017b) has spoken about the need to utilize the RNR model in athlete violence from a prevention, assessment, and treatment point of view. Prevention must address the many factors that can contribute to athlete violence, including those often embedded and interwoven in the male athlete culture. Bystander Intervention is a minor part of the modelbecause the author appreciated, especially in team sport dynamics, a lesser status athlete is less likely to stand up to more influential seniors, especially if they are acting in a way that is overtly or covertly supported by the coaches and administrators above them. With a primary focus on culture change, interventions need to utilize both a top-down and bottomup approach and include addressing the myth of false reports and victim prototype, the legalities of consent, drug and alcohol education, consequences, and the male athlete culture. 
Addressing the myth of false reports. Often athletes believe allegations of false reports are common, so, when providing statistics to athletes about victimization, it is critical to include that false reports of sexual assault occur, according to FBI statistics, at the same rate as any other crime (2-5\%; Lisak, Gardinier, Nicksa, \& Cote, 2010), which is very rare. It is far more likely that a victim will not come forward than make a false report (63\%, Rennison, 2002). This may be due to the isolation that accompanies the trauma, which is compounded by people not believing them or shaming them, as if they were willful participants in their victimization. If one adds the retraumatization that occurs in the administration of a Sexual Assault Forensic Examination (see also Abrams, 2010, p. 224) and in crossexamination where Rape Shield laws have not protected victims, the likelihood of false report is again exceedingly unlikely in comparison to an unreported rape.

Addressing the myth of the victim prototype. When presenting on incidence rates, it is important to help male athletes understand that sexual assault affects them, as well. This is because given incidence rates, it is nearly impossible that they do not know someone who has been a victim; not to mention the much higher incidence of male victimization than people realize (Bullock \& Beckson, 2011). Understanding in this domain is in its infancy, as it is recognized that hazing in male sports has, at its core, victimization based upon power differentials, and sometimes that victimization is sexual (Heil, Martin, \& Kavussanu, 2016). Male athletes may have been a victim of sexual assault during hazing rituals without realizing it.

Addressing the legalities of consent. The next component addressed in the RNR model is discussion about the legalities of consent. Many people do not understand, appreciate or agree with what is necessary to constitute consent (Witmer-Rich, 2016). Attention must be paid to statutory limitations that delineate how old an individual must be to legally give consent. This is also complicated by differences from state to state on how sex crimes are defined. Issues of incapacitation, including being unconscious, mentally ill and/or intoxicated (by substances they ingested or those that were slipped into their drinks to incapacitate them) must be addressed. Also, when discussing consent, it should be highlighted to audiences that some states have "Forcible Compulsion" components of their sexual assault statutes, whereby it is a sexual assault when a person complies with sexual activity for fear of being harmed if they do not comply; and that threat can be overt or implied. Male athletes may be confused when they hear this, but it is critical for them to understand two things: 1 . Laws have shifted because the laws have done such a poor job of assisting victims and leading to prosecution and 2. Regardless of whether one agrees with a law, one should still be educated about what the law is that must be followed.

Drug and alcohol education. This leads to the next content area: drug and alcohol education. There is little confusion that alcohol can be used as a weapon in an attempt to make women more susceptible to the advances of men. It is the reason why "Ladies Drink Free" specials are seen at clubs and bars. There are some who have challenged that drug and alcohol education is akin to blaming the victim. Drinking to the point of incapacitation can be poor judgment. However, poor judgment on the part of the victim does not justify the rape. Encouraging individuals to exercise better judgment can also be advantageous. Studies have 
shown that athletes engage in frequent bouts of binge drinking (Brenner \& Swanik, 2007; Yusko, Buckman, White, \& Pandina, 2008), pointing to the need for alcohol education. Alcohol intoxication is not a defense that will be effective in avoiding culpability in sexual assault cases (Go, 2017).

Addressing consequences. Perhaps the penultimate conversation that could have lasting impact is discussing with young male athletes what prison is like. Being able to explain the phenomenology of incarceration, such as a lack of the most basic freedoms, an ever-present threat of violence, extorsion, and guard indifference, can have eye-opening reactions. All in all, being able to share with young men what incarceration is really like, should they wind up there, is a powerful part of prevention programming.

Addressing male athlete culture. There is also the issue of the male athlete culture in general. The athlete culture, in and of itself, suppresses the willingness of athletes to discuss their emotional struggles and a stigma that seeking psychological help is a sign of weakness (Wahto, Swift, \& Whipple, 2016). Often the misogynistic themes that can be seen in locker room talk objectifies females, idealizes female conquests, legitimizes rape, promotes homophobia and equates femininity with weakness (a poor performing male athlete may be teased for throwing like a girl or having some other feminine characteristic), or any theme of status, toughness, and anti-femininity (Leone \& Parrott, 2019). This can be compounded by the belief that the coach/staff will fix any transgression an athlete or staff member engages in. However, we should also be mindful that our society (parents, coaches, athletes, etc.), continues to fuel the athletically talented individual with the idea that they have a different set of rules (Coakley, 2017).

This need for a culture shift exists far before the student-athlete understands what college athletics consists of; leaving universities responsible to remediate athlete entitlement. Accountability should be demanded overtly at all levels of sport participation, but specific attention must be added to youth sports where the athletes may be more plastic and receptive (Bavelier et al., 2010).

When coaches and administrators, especially males, set the tone that abuse of women will absolutely not be tolerated, and levy swift consequences regardless of the talent level of the perpetrator, change may start. To incite change it is also important to pay attention to the attitudes that the male athletes embrace and how group dynamics can lead them to an epidemic of sexual acting out. Groupthink (Janis, 1972) can lead to deindividuation where someone who normally has a good set of morals and would not engage in deviant behavior, joins in the group attitude and takes part in collective, systematic misogyny. The presence of a misogynistic peer norm also decreases the likelihood of prosocial bystander intervention in males (Leone \& Parrott, 2019).

A crucial factor related to culture that needs to be highlighted and targeted for intervention is Toxic (or Hostile) Masculinity (Malamuth \& Thornhill, 1994; Malamuth et al., 1996), which is a prevailing set of attitudes predicated upon male dominance, devaluation of women, misogyny, suppression of emotions and homophobia. It is the backbone of "locker room talk" (see also Stripling (2017) for examples) and may lead boys, who often struggle with self-esteem, to question what it means to be a man. Malamuth and colleagues posited in the Confluence Model of Sexual Aggression (1994, 1996), that it is the combination of hostile 
masculinity and impersonal sex that creates an explosive mixture that sets the stage for assault. It may be puzzling how, when these factors often converge on college campuses, this has not been a major focus of intervention. . especially since the model has been around for over twenty years.

Again, hostile masculinity, may be further exacerbated by the male athlete culture that restricts allowing athletes to experience, process, and utilize their emotions (Wahto et al., 2016). The concepts of respect, honor, integrity and loyalty are often used as hashtags rather than being qualities that are valued and nurtured. Ultimately, sports administrators and coaches MUST demand accountability and high moral character. Unfortunately, the teams, coaches and organizations often share culpability either because they knew about the problem and didn't get the athlete the help they need, or they did not know and they should have.

Further, for many athletes, especially those coming from single-parent households, coaches can provide the guidance and male role-modeling that they are not getting otherwise. There may be many coaches that are effectively saving these boys' lives. However, there is compelling evidence in the incidence rates that male athletes are not consistently getting clear messages demanding respect for females and that there will be zero tolerance, regardless of the physical abilities of the athlete, for any deviance from this credo. Athlete populations must be sensitive to the Toxic Masculinity that may be present in the male athlete culture and work to contradict it. Severe punishment is necessary as a deterrent, but it is insufficient alone. Better prevention and risk assessment is needed to determine the best course of action. Because prevention does not require clinical acumen per se, it can be particularly powerful to have former/ current athletes work in presentations to change the culture.

Culture shift requires team leadership, coaches, and captains to carry the torch of acceptable behavior, with coaches potentially being fired if continually perpetuating an adverse culture (Stripling, 2017). Playing sports, especially at the college and professional level, is a privilege, not a right. And athletics departments and sport organizations can do a better job of holding their coaches, staff, and studentathletes accountable. Similarly, treatment of sexual and domestic violence also needs to be handled by professionals with expertise and training in such areas that may not be standard in all relevant graduate education. The importance of using a three-pronged approach: comprehensive prevention, risk assessment, and treatment, cannot be underestimated in moving toward reduction of sexual assault incidences and victims, and the world of athletics is no exception.

\section{Summary}

Violence is not a new phenomenon in American society and, not surprisingly, it is represented in the sport culture, as well. The \#MeToo movement has brought to the forefront the need to talk about victimization openly and honestly in sport; while also setting the stage for change. In conclusion, there is a great need to identify both victims and perpetrators of sexual abuse and violence, with the hopes of delivering services to victims that have been historically under attended to, and to perpetrators, with the hope of addressing their criminogenic factors.

It is prudent then, to progress towards a three-prong approach to target sexual assault in athlete populations focusing upon comprehensive programming, risk 
assessment and treatment for perpetrators. Comprehensive programming that targets hostile masculinity, teaches the legalities of consent, provides drug and alcohol education, discusses incidence rates and consequences for all parties involved must supplant the proliferated Bystander Interventions which have not proven to lead to lasting change. Culture shifts will require longer, ongoing interventions, rather than single session "shotgun" approaches.

Moreover, an appreciation that the skills required to change approaches to sexual assault prevention lay at the intersection of clinical, forensic and sport psychology is long overdue. We must bring experts with these backgrounds together to implement programmatic change. This must include consideration of the Risk Needs Responsivity approach utilizing Structured Professional Judgment to identify sport-involved-perpetrators (athletes, coaches and staff) and, when indicated, provide treatment to them to reduce their potential for recidivism. If treatment is not provided, the perpetrator may move on to another area where their offending history is unknown and secure more victims.

\section{References}

Abrams, M. (2010). Anger management in sport. Champaign, IL: Human Kinetics.

Abrams, M. (August, 2017a). Models to address campus sexual assault: History and new directions. In Division 41-American Psychology-Law Society (Chair), Sexual violence on campus-Changing dialogue, changing culture. Symposium conducted at the meeting of American Psychological Association Annual Convention, Washington, DC.

Abrams, M. (October, 2017b). Sexual \& domestic violence in athletes: Prevention, treatment \& assessing risk. Workshop presented at the Association for Applied Sport Psychology Annual Conference, Orlando, FL.

Andrews, D.A., \& Bonta, J. (1998). The psychology of criminal conduct. Cincinnati, OH: Anderson Publishing Company.

Bavelier, D., Levi, D.M., Li, R.W., Yang, D., \& Hensch, T.K. (2010). Removing brakes on adult brain plasticity: From molecular to behavioral interventions. The Journal of Neuroscience, 30(45), 14964-14971. PubMed ID: 21068299 doi:10.1523/ JNEUROSCI.4812-10.2010

Brenner, J., \& Swanik, K. (2007). High-risk drinking characteristics in collegiate athletes. Journal of American College Health, 56(3), 267-272. PubMed ID: 18089508 doi:10. 3200/JACH.56.3.267-272

Bullock, C.M., \& Beckson, M. (2011). Male victims of sexual assault: Phenomenology, psychology, \& physiology. The Journal of the American Academy of Psychiatry and the Law, 39(2), 197-205. PubMed ID: 21653264

Butcher, J.N., Graham, J.R., Ben-Porath, Y.S., Tellegen, A., Dahlstrom, W.G., \& Kaemmer, B. (2001). MMPI-2:Manual for administration and scoring (Rev. ed.). Minneapolis, MN: University of Minnesota Press.

Cantor, D., Fisher, B., Chibnall, S., Bruce, C., Townsend, R., Thomas, G., \& Lee, H. (2015). Report on the AAU campus climate survey on sexual assault and sexual misconduct. Retrieved from http://www.upenn.edu/ir/surveys/AAU/Report\%20and\%20Tables\% 20on\%20AAU\%20Campus\%20Climate\%20Survey.pdf

Caron, S.L., Halteman, W.A., \& Stacy, C. (1997). Athletes and rape: Is there a connection? Perceptual and Motor Skills, 85(3), 1379-1393. doi:10.2466/pms.1997.85.3f.1379

Casey, E.A., \& Ohler, K. (2012). Being a positive bystander: Male antiviolence allies' experiences of stepping up. Journal of Interpersonal Violence, 27(1), 62-83. PubMed ID: 21859757 doi:10.1177/0886260511416479 
Coakley, J. (2017). Sports in society: Issues and controversies (12th ed.). New York, NY: McGraw-Hill Education.

Conley, A.H., Overstreet, C.M., Hawn, S.E., Kendler, K.S., Dick, D.M., \& Amstadter, A.B. (2017). Prevalence and predictors of sexual assault among a college sample. Journal of American College Health, 65(1), 41-49. PubMed ID: 27628533 doi:10.1080/ 07448481.2016 .1235578

Coray, E. (2016). Victim protection or revictimization: Should college disciplinary boards handle sexual assault claims? Boston College Journal of Law \& Social Justice, 36, 59-90.

Craven, S., Brown, S., \& Gilchrist, E. (2006). Sexual grooming of children: Review of literature and theoretical considerations. Journal of Sexual Aggression, 12, 287-299. doi:10.1080/13552600601069414

Darley, J.M., \& Latane, B. (1968). Bystander intervention in emergencies: Diffusion of responsibility. Journal of Personality and Social Psychology, 8(4, Pt. 1), 377-383. doi: $10.1037 / \mathrm{h} 0025589$

Douglas, K.S., Hart, S.D., Webster, C.D., \& Belfrage, H. (2013). HCR-20V3: Assessing risk of violence-User guide. Burnaby, Canada: Mental Health, Law, and Policy Institute, Simon Fraser University.

Douglas, K.S., \& Kropp, P.R. (2002). A prevention-based paradigm for violence risk assessment: Clinical and research applications. Criminal Justice and Behavior, 29(5), $617-658$.

Douglas, K.S., \& Webster, C.D. (1999). Predicting violence in mentally and personality disordered individuals. In R. Roesch, S.D. Hart, \& J.R.P. Ogloff (Eds.), Psychology and Law: The state of the discipline (pp. 175-239). New York, NY: Plenum.

Dube, S.R., Anda, R.F., Whitfield, C.L., Brown, D.W., Felitti, V.J., Dong, M., \& Giles, W.H. (2005). Long-term consequences of childhood sexual abuse by gender of victim. American Journal of Preventive Medicine, 28(5), 430-438. PubMed ID: 15894146 doi:10.1016/j.amepre.2005.01.015

Eskenazi, G. (1990, June 3). The male athletes and sexual assault. The New York Times, pp. 1,4 .

Exner, J.E. (2002). The Rorschach, A comprehensive system, volume 1, basic foundations and principles of interpretation. (4th ed.). New York, NY: Wiley.

Fedina, L., Holmes, J.L., \& Backes, B.L. (2016). Campus sexual assault: A systematic review of prevalence research from 2000-2015. Trauma, Violence, \& Abuse, 19(1), 76-93. PubMed ID: 26906086 doi:10.1177/1524838016631129

Finkelhor, D., Shattuck, A., Turner, H.A., Hamby, S.L. (2014). The lifetime prevalence of child sexual abuse and sexual assault assessed in late adolescence. Journal of Adolescent Health, 55, 329-333. PubMed ID: 24582321 doi:10.1016/j.jadohealth. 2013.12.026

Fischer, P., Krueger, J., Greitemeyer, T., Vogrincic, C., Kastenmüller, A., Frey, D., . . . Kainbacher, M. (2011). The bystander-effect: A meta-analytic review on bystander intervention in dangerous and non-dangerous emergencies. Psychological Bulletin, 137(4), 517-537.

Go, G. (2017). Amnesia and criminal responsibility. Journal of Law and the Biosciences, 4(1), 194-204. PubMed ID: 28781882 doi:10.1093/jlb/lsx003

Grove, W.M., \& Meehl, P.E. (1996). Comparative efficiency of informal (subjective, impressionistic) and formal (mechanical, algorithmic) prediction procedures: The clinical-statistical controversy. Psychology, Public Policy, and Law, 8, 5-23.

Hanson, R.K., \& Bussiere, M.T. (1998). Predicting relapse: A meta-analysis of sexual offender recidivism studies. Journal of Consulting and Clinical Psychology, 66, 348-362. PubMed ID: 9583338 doi:10.1037/0022-006X.66.2.348 
Hanson, R.K., \& Morton-Bourgon, K. (2004). Predictors of sexual recidivism: An updated meta-analysis. User Report 2004-02. Ottawa, Canada: Public Works and Government Services Canada.

Hart, S.D. (1998). The role of psychopathy in assessing risk for violence: Conceptual and methodological issues. Legal and Criminological Psychology, 3, 121-137.

Hart, S.D., Cox, D.N., \& Hare, R.D. (1995). Manual for the Hare Psychopathy Checklist: Screening Version (PCL:SV). Toronto, Canada: Multi-Health Systems.

Heil, J., Martin, J., \& Kavussanu, M. (2016). Sport advocacy: challenge, controversy, ethics, and action. Sport, Exercise, and Performance Psychology, 5(4), 281-295. doi:10.1037/ spy0000078

Heppner, M., Neville, H., Smith, K., Kivlighan, D., Gershuny, B., \& Hill, C. (1999). Examining immediate and long-term efficacy of rape prevention programming with racially diverse college men. Journal of Counseling Psychology, 46(1), 16-26. doi:10. 1037/0022-0167.46.1.16

Holland, K.J., \& Cortina, L.M. (2017). "It happens to girls all the time": Examining sexual assault survivors' reasons for not using campus supports. American Journal of Community Psychology, 59(1-2), 50-64. doi:10.1002/ajcp.12126

Humphrey, S., \& Kahn, A. (2000). Fraternities, athletic teams, and rape: Importance of identification with a risky group. Journal of Interpersonal Violence, 15(12), 13131322. doi:10.1177/088626000015012005

Janis, I.L. (1972). Victims of groupthink: a psychological study of foreign-policy decisions and fiascoes. Boston, MA: Houghton Mifflin.

Katz, J. (1995). Reconstructing masculinity in the locker room: The mentors in violence prevention project. Harvard Educational Review, 65(2), 163-175.

Katz, J., Merrilees, C., Hoxmeier, J.C., \& Motisi, M. (2017). White female bystanders' response to a black womn at risk for incapacitate sexual assault. Psychology of Women Quarterly, 41(2), 273-285. doi:10.1177/0361684316689367

Katz, J., \& Moore, J. (2013). Bystander education training for campus sexual assault prevention: An initial meta-analysis. Violence and Victims, 28(6), 1054-1067. doi:10. 1891/0886-6708.VV-D-12-00113

Kropp, P.R., Hart, S.D., Webster, C.W., \& Eaves, D. (1995). Manual for the spousal assault risk assessment guide (2nd ed.). Vancouver, Canada: B.C. Institute on Family Violence.

Labhardt, D., Holdsworth, E., Brown, S., \& Howat, D. (2017). You see but you do not observe: A review of bystander intervention and sexual assault on university campuses. Aggression \& Violent Behavior, 35, 13-25. doi:10.1016/j.avb.2017.05.005

Leone, R.M., \& Parrott, D.J. (2019). Misogynistic peers, masculinity, and bystander intervention for sexual aggression: Is it really just "locker room talk"? Aggressive Behavior, 45(1), 42-51. doi:10.1002/ab.21795

Leone, R.M, Parrott, D.J., \& Swartout, K.M. (2017). When is it "manly" to intervene?: Examining the effects of a misogynistic peer norm on bystander intervention for sexual aggression. Psychology of Violence, 7(2), 286-295. doi:10.1037/vio0000055

Lisak, D., Gardinier, L., Nicksa, S.C., \& Cote, A.M. (2010). False allegations of sexual assault: An analysis of ten years of reported cases. Violence Against Women, 16(12), 1318-1334. PubMed ID: 21164210 doi:10.1177/1077801210387747

Litwack, T.R. (2001). Actuarial versus clinical assessments of dangerousness. Psychology, Public Policy, and Law, 7, 409-443. doi:10.1037/1076-8971.7.2.409

Litwack, T.R., \& Schlesinger, L.B. (1999). Dangerousness risk assessments: Research, legal and clinical considerations. In A.K. Hess \& I.B. Weiner (Eds.), Handbook of Forensic Psychology (2nd ed., pp. 171-217). New York, NY: Wiley.

Malamuth, N.M., Heavey, C.L., \& Linz, D. (1996). The confluence model of sexual aggression: Combining hostile masculinity and impersonal sex. Sex Offender Treatment, 23(3-4), 13-37. doi:10.1300/J076v23n03_03 
Malamuth, N.M., \& Thornhill, N.W. (1994). Hostile masculinity, sexual aggression, and gender-biased domineeringness in conversions. Aggressive Behavior, 20, 185-193. doi:10.1002/1098-2337(1994)20:3<185::AID-AB2480200305>3.0.CO;2-3

Marchell, T.C. (1998). Sexual and physical aggression against women by male college athletes. Dissertation Abstracts International: Section B: The Sciences and Engineering, 58(11-B), 6269.

Morey, L.C. (2007). The personality assessment inventory professional manual. Lutz, FL: Psychological Assessment Resources.

National Collegiate Athletic Association. (n.d.). Bystander intervention. Retrieved from http://www.ncaa.org/sport-science-institute/topics/bystander-intervention

Navarro, J.C., \& Tewksbury, R. (2017). National comparisons of rape myth acceptance predictors between nonathletes and athletes from multi-institutional settings. Sexual Abuse: A Journal of Research and Treatment,1-17. doi:10.1177/1079063217732790

New, J. (2015, September). The 'invisible' one in four. Inside Higher Ed. Retrieved from https://www.insidehighered.com/news/2015/09/25/1-4-transgender-students-say-theyhave-been-sexually-assaulted-survey-finds

Phenix, A., Helmus, L., Hanson, R.K. (2012). Static-99R \& Static-2002R evaluators' workbook. Retrieved from www.static99.org

Quinsey, V.L., Harris, G.T., Rice, G.T., \& Cormier, C.A. (1998). Violent Offenders: Appraising and managing risk. Washington, DC: American Psychological Association.

Rennison, C.A. (2002). Rape and sexual assault: Reporting to police and medical attention, 1992-2000 [NCJ 194530]. Retrieved from http://bjs.ojp.usdoj.gov/content/pub/pdf/ rsarp00.pdf

Robers, S., Kemp, J., Rathbun, A., Morgan, R.E., \& Snyder, T.D. (2014). Indicators of school crime and safety: 2013. Retrieved from https://timedotcom.files.wordpress. com/2014/06/2014042.pdf

Roth, S., Newman, E., Pelcovitz, D., van der Kolk, B., \& Mandel, F. (1997). Complex PTSD in victims exposed to sexual and physical abuse: Results from the DSM-IV field trial for posttraumatic stress disorder. Journal of Traumatic Stress, 10(4), 539-555. PubMed ID: 9391940

Sinden, J.L. (2013). The sociology of emotion in elite sport: Examining the role of normalization and technologies. International Review for the Sociology of Sport, 48(5), 613-628. doi:10.1177/1012690212445274

Smith, D., \& Stewart, S. (2003). Sexual aggression and sports participation. Journal of Sport Behavior, 26(4), 384-396.

Spielberger, C.D. (1999). Professional manual for the state-trait anger expression inventory-2 (STAXI-2). Odessa, FL: Psychological Assessments Resources, Inc.

Storer, H.L., Casey, E., \& Herrenkohl, T. (2016). Efficacy of bystander programs to prevent dating abuse among youth and young adults. Trauma, Violence, \& Abuse, 17(3), 256-269. PubMed ID: 25951840 doi:10.1177/1524838015584361

Stripling, J. (2017). Behind ugly locker-room talk, divisions of class and race. The Chronicle of Higher Education, 63(25), A13-A17.

The Chronicle of Higher Education. (2018). Title IX: Tracking Sexual Assault Investigations [Software]. Retrieved from https://projects.chronicle.com/titleix/?cid=T9WIDGET

Vladutiu, C., Martin, S., \& Macy, R. (2011). College- or university-based sexual assault prevention programs: A review of program outcomes, characteristics, and recommendations. Trauma, Violence, \& Abuse, 12(2), 67-86. PubMed ID: 21196436 doi:10. $1177 / 1524838010390708$

Wahto, R.S., Swift, J.K., \& Whipple, J.L. (2016). The role of stigma and referral source in predicting college student-athletes' attitudes toward psychological helpseeking. Journal of Clinical Sport Psychology, 10(2), 85-98. doi:10.1123/JCSP. 2015-0025 
Ward, T. (2002). Good lives and the rehabilitation of offenders: promises and problems. Aggression and Violent Behavior, 7, 513-528. doi:10.1016/S13591789(01)00076-3

Ward, T., Melser, J., \& Yates, P.M. (2007). Reconstructing the risk need responsivity model: A theoretical elaboration and evaluation. Aggression and Violent Behavior, 12, 208-228. doi:10.1016/j.avb.2006.07.001

Weiner, I.B. (2005). The utility of Rorschach assessment in clinical and forensic practice. Independent Practitioner, 25(2), 76-83.

Williams, D.J., \& Neville, F.G. (2017). Qualitative evaluation of the mentors in violence prevention pilot in Scottish high schools. Psychology of Violence, 7(2), 213-223. doi: $10.1037 /$ vio0000046

Willis, G.M., \& Ward, T. (2010). Striving for a good life: The good lives model applied to released child molesters. Journal of Sexual Aggression, 17(3), 290-303. doi:10.1080/ 13552600.2010 .505349

Witmer-Rich, J. (2016). Unpacking affirmative consent: Not as great as you hope, not as bad as you fear. Law Faculty Articles and Essays, 901, 57-88.

Yusko, D., Buckman, J., White, H., \& Pandina, R. (2008). Alcohol, tobacco, illicit drugs, and performance enhancers: A comparison of use by college student athletes and nonathletes. Journal of American College Health, 57(3), 281-290. PubMed ID: 18980883 doi:10.3200/JACH.57.3.281-290 